\title{
Comprehensive Income Presentation According to IAS 1 in Italy and in the United Kingdom: A Comparison of Preparers' Opinions
}

\author{
Barbara Falzago (Corresponding author) \\ Ph.D in Economics and Business \\ Department of Economics, 'G. d'Annunzio' University of Chieti/Pescara (Italy) \\ Email: b.falzago@unich.it \\ Tiziana De Cristofaro \\ Assistant Professor of Accounting and Business Administration \\ Department of Economics, 'G. d'Annunzio' University of Chieti/Pescara (Italy) ${ }^{\mathrm{i}}$
}

Received: November 08, 2016 Accepted: November 28, 2016 Published: December 18, 2016 doi:10.5296/ijafr.v6i2.10278 URL: http://dx.doi.org/10.5296/ijafr.v6i2.10278

\begin{abstract}
Studies investigating the reasons behind corporate choices on the format of their Comprehensive Income Statement (CIS) have so far relied on research tools other than surveys and interviews, neglecting direct analysis. Our aim was to investigate the reasons behind CIS format preferences in European countries with different accounting cultures; therefore, we researched Italian and British listed companies offering non-financial services and the reasons for their preferences using a survey-based approach. Our findings show that: (i) preparers deem the Comprehensive Income a performance measure mainly useful to 'financial' stakeholders; (ii) the two-statement format and its stability prevail; (iii) the main reasons driving format choices are easy reading and interest in Profit and Loss (P/L)if the preference is for two statements, and simplicity for readers and preparers in the case of one statement; (iv) Other Comprehensive Income related reasons are the least important for format choices; (v) while British preparers focus on their interest in P/L(two statements)or easy reading (one statement) as the 'bottom line' determining their choice, Italian preparers focus on easy reading only in case of one statement, while also deeming important their interest in P/L in case of two statements; (vi) British preparers emphasize the easy preparation of financial statements more than their Italian counterparts.Hence, despite some
\end{abstract}


differences, the two countries are aligned in considering reader-oriented reasons in their format choice.This means that, contrary to what could be reasonablyexpected, different accounting cultures can choose the same CIS format because of the same reasons.

Keywords: IAS 1, Financial Statements Presentation, Comprehensive Income Statement, Italy, United Kingdom

\section{Introduction}

Since the 2007 version, IAS 1 introduced two possible formats for the Income Statement:

(1) the single-statement format joins Profit and Loss (P/L hereinafter) with gains and losses directly recognized as equity (all together forming the Other Comprehensive Income - OCI hereinafter) in one statement; this ends with a wider performance measure tending towards the Comprehensive Income (CI hereinafter);

(2) the two-statement format reports P/L items in the first statement, while the second starts with $\mathrm{P} / \mathrm{L}$, reports OCI items and ends with $\mathrm{CI}$.

Listed companies in the European Union (EU) must apply IASs/IFRSs since Regulation EC 1606/2002; until 2002, the concept of CI was known only by Anglo-Saxon countries. In fact, with Financial Reporting Standard - FRS 3 (1992) the United Kingdom Accounting Standards Board (ASB) requested a 'statement of total recognised gains and losses' including both the profit for the year and other unrealised gains and losses. Hence, although a mandatory format was not set by FRS 3, CI and a performance-based presentation of the OCI items entered the British accounting culture before other EU countries and the IAS1 $2007^{\mathrm{ii}}$. It follows that only since the turn of the millennium have scholars been interested in CI issues applied to the EU context.

The literature about CI presentation in Europe can be split into two main branches:

a) literature on the format chosen for CI reporting ${ }^{\text {iii }}$, whose findings show that the twostatement format is the preferred option in EU countries;

b) literature on the reasons for the format preference.

This paper contributes to the latter branch, helping to shed light on two critical issues emerging from the relevant literature of the last decade.

The first issue originates from the approach used to study the reasons behind format choices. Studies included in the second branch investigate reasons using the mainstream U.S. approach. This approach explains format preferences through statistical associations with 'technical' variables from financial statements (e.g. accounting items and company size). This indirect approach infers preferences using preparers' outputs (i.e. financial statements) rather than their opinions (direct approach). Alternatively, when statistical tools are not used, other reasons are only suggested in a narrative way. Very few studies have directly elicited opinions from users (see Maines \& McDaniel, 2000) and preparers on CI usefulness; no studies seem 
to have directly elicited opinions from preparers about the reasons for their format choices. Hence, a methodological gap emerges within the above-mentioned research branch.

The second critical issue originates from the findings of contributions that studied EU companies in terms of their format choices and the reasons behind these. A low or null association emerged between the above-mentioned 'technical' variables and the formats chosen; this seems to suggest that new research should look elsewhere to identify the motivations affecting preparers' preferences. For example, as recalled by Cimini $(2013,14)$, it was hypothesised that format choices could be influenced by economic-context-related reasons (e.g. weak equity market capitalization). Subsequent studies (e.g. Huff \& Delcoure, 2014) showed that countries characterized by differently developed financial markets and accounting culture ${ }^{\text {iv }}$ selected the same format. These findings implicitly supported the view that economic/cultural reasons alone may not be able to explain format choices fully. The issue, however, can be looked at from the opposite perspective: why do very different countries select the same format?

The joint consideration of the first (lack of studies based on a direct approach) and second (culturally/economically different countries prefer the same format) critical issues generates our basic aim. The current paper uses a direct approach to the preparers' perspective in order to compare the reasons behind format preferences; the research is carried out on companies operating in two EU countries that prefer the same format despite different financial markets and accounting cultures. The selected cases are Italy (characterized by a not fully developed financial market and a continental accounting culture), and the United Kingdom, (characterized by a developed financial market and an Anglo-Saxon accounting culture).

To achieve our basic research goal, we administered a web-mail survey to Italian and British listed companies offering non-financial services that closed Financial Statements in 2012. The preparers' opinions were elicited about the three following aspects: 1) CI usefulness; 2) the preferred Comprehensive Income Statement (CIS hereinafter) format; 3) reasons underlying format choices.

In our opinion, this paper could interest the following categories of subjects: (i) preparers, who can find useful information on the viewpoints of other preparers operating within the same/a culturally different country; (ii) stakeholders, who can compare their views with the preparers' (iii) standard setters, who can harness the viewpoint of preparers other than those who commented the IAS1 setting process directly.

The remainder of the paper discusses the relevant literature, the paper's research design and the methods used. Results are presented and discussed together in a separate section. Finally, the last section includes conclusions, limitations and input for further studies.

\section{Bibliographic Framework}

This research aims to analyse the reasons for CIS format choices in European countries with different financial markets and accounting culture. When we looked for relevant contributions from the literature, we found that the CI-presentation related literature can be split into two main branches, i.e. a first branch investigating the preferred CIS format and a 


\section{Macrothink}

International Journal of Accounting and Financial Reporting

ISSN 2162-3082

2016, Vol. 6, No. 2

second oriented to the reasons for such preference. In this section we focus on the latter branch.

More in detail, in our review we include both studies on IAS/IFRS and US GAAP (as U.S. listed companies can use an OCI performance-based presentation since 1998). On the other hand, our review excludes (1) studies focusing on the U.S. and/or the EU context when these do not try to explain CI format choices and (2) studies focusing on EU contexts not written in English, due to their unavailability to international scholars. After these exclusions, the analysis of the resulting literature dealing with the reasons behind the CIS format led us to the classification shown in Table 1.

The selected literature was first classified according to the subjects whose viewpoint is considered (users or preparers) when the reasons behind the format choices are addressed, resulting in two table sections ("A - User-oriented" and "B - Preparer-oriented"). Within the two sections we list referenced contributions (Column 2) according to the reason they address (Column 1). The table does not highlight the format considered by the studies as this is not our main aim .

The "user-oriented" reasons are the following (see Table 1):

- format choices are influenced by accounting items (i.e. OCI and P/L) whose features (e.g. OCI sign) can influence the users' judgement (see reason I-a of Table 1). Moreover, sometimes the users' opinions about the importance of hiding or highlighting a value (respectively OCI and P/L) are deemed relevant for the format choice process (see reasons I-b and I-c);

- format choices could be caused by different levels of development of financial markets; this may be because the different groups of users who are the most interested in the financial statements of weak and of strong equity markets could determine a different kind of information disclosure (see reason II);

- format choices could depend on the desire to facilitate reading, interpretation and comparison of financial statements (see reason III).

Table 1: Relevant literature on CIS formats: main proposed reasons for the preferred option

\begin{tabular}{|c|c|c|c|c|c|}
\hline \multirow{3}{*}{ (1) Reason } & \multirow{3}{*}{ (2) Reference } & \multirow{3}{*}{ (3) Country } & \multicolumn{3}{|c|}{ (4) Approach } \\
\hline & & & \multicolumn{2}{|c|}{$\begin{array}{l}\text { Reasons are } \\
\text { investigated }\end{array}$} & \multirow{2}{*}{$\begin{array}{l}\text { Reasons } \\
\text { are } \\
\text { suggested }\end{array}$} \\
\hline & & & $\mathrm{D}^{*}$ & $\mathrm{I}^{* *}$ & \\
\hline \multicolumn{6}{|c|}{ (A) User-oriented reasons } \\
\hline I)Accounting & $\begin{array}{l}\text { Cimini 2013, De Cristofaro } \\
\& \text { Falzago 2014, Ferraro }\end{array}$ & Italy & - & $X$ & - \\
\hline
\end{tabular}




\begin{tabular}{|c|c|c|c|c|c|}
\hline $\begin{array}{l}\text { item: } \\
\text { I-a) OCI's and } \\
\text { NI's features }\end{array}$ & $\begin{array}{l}\text { 2011, Ferraro } 2012 \\
\text { Gazzola-Amelio } 2012\end{array}$ & $\begin{array}{l}\text { Czech } \\
\text { Republic }\end{array}$ & & & \\
\hline $\begin{array}{l}\text { I-b) Obscuration } \\
\text { of the OCI }\end{array}$ & Pandit 2004 & U.S.A. & - & $X$ & - \\
\hline $\begin{array}{l}\text { I-c) NI } \\
\text { importance }\end{array}$ & Szychta-De la Rosa 2012 & Poland & - & $\mathrm{X}$ & - \\
\hline $\begin{array}{l}\text { II) Market } \\
\text { capitalization }\end{array}$ & Cimini 2013 & Italy & - & - & $\mathrm{X}$ \\
\hline $\begin{array}{l}\text { III) Reading } \\
\text { (easy } \\
\text { interpretation/ } \\
\text { comparison) }\end{array}$ & $\begin{array}{l}\text { Ferraro } 2011 \\
\text { Ngmenipuo } 2014\end{array}$ & $\begin{array}{l}\text { Italy } \\
\text { Ghana }\end{array}$ & - & - & $\mathrm{X}$ \\
\hline
\end{tabular}

(B) Preparer-oriented reasons

\begin{tabular}{|l|l|l|l|l|l|}
\hline $\begin{array}{l}\text { IV) Companies' } \\
\text { features (size) }\end{array}$ & $\begin{array}{l}\text { Cimini 2013 } \\
\text { Frendzel-Szycth 2013 }\end{array}$ & $\begin{array}{l}\text { Italy } \\
\text { Poland }\end{array}$ & - & - & $\mathrm{X}$ \\
\hline $\begin{array}{l}\text { V) Intimate } \\
\text { understanding } \\
\text { of the OCI role }\end{array}$ & Gazzola-Amelio 2014 & $\begin{array}{l}\text { Czech } \\
\text { Republic }\end{array}$ & - & - & $\mathrm{X}$ \\
\hline VI) Habitude & Pandit 2004, Pandit 2006 & U.S.A. & - & - & $\mathrm{X}$ \\
\hline $\begin{array}{l}\text { VII) Familiarity } \\
\text { Agostini-Marcon 2013, De } \\
\text { Cristofaro-Falzago 2014 }\end{array}$ & $\begin{array}{l}\text { Italy } \\
\text { Ngmenipuo 2014 }\end{array}$ & $\begin{array}{l}\text { Ghana } \\
\text { U.S.A., Italy, } \\
\text { China, Japan, } \\
\text { France, UK, } \\
\text { Germany, } \\
\text { and } \\
\text { others*** }\end{array}$ & X & - & X \\
\hline $\begin{array}{l}\text { Unfamiliarity } \\
\text { with OCI }\end{array}$ & Huff-Delcoure 2014 & - & \\
\hline
\end{tabular}

(*) Direct approach (**) Indirect approach (***) Australia, Brazil, Canada, Denmark, 
Finland, India, Luxembourg, Netherlands, Norway, Russia, Scotland, S. Korea, Spain, Switzerland, Taiwan, Thailand, Vietnam

The "preparer-oriented" reasons are the following (see Table 1):

- format choices could depend on company features such as the company's size (see reason IV);

- format choices can be related to the preparers' understanding of the OCI's specific meaning and informative role (see reason $\mathrm{V}$ );

- format choices can be simply dependent on the preparers' accounting habits (see reason VI), on their technical familiarity with a format (see reason VII) and on their lack of familiarity with new accounting items such as OCI (reason VIII).

The countries considered (see column 3) mainly belong to the U.S. and the EU. Finally, column 4 of the table considers the research approach used by the authors. This column separates studies in which reasons are investigated using statistical tools from studies in which reasons are suggested narratively without a statistical basis. Since the two approaches (statistical investigation and narrative suggestion) cannot co-exist, a study cannot belong to both categories. More in detail, the sub-column devoted to the investigative approach was further split into two columns (D and I). These indicate the use of a direct (D) or an indirect (I) approach to the investigation. By 'direct' approach we mean an approach that implies direct contact (e.g. interviews, surveys) with users or preparers. On the contrary, by 'indirect' approach we mean an approach that lacks direct contact with the above-mentioned subjects, making use of documentation instead (e.g. financial statement analysis). The latter approach infers the existence of reasons through statistical association between the format chosen and objective features (such as the OCI or the company size) obtainable by consulting official sources $^{\mathrm{vi}}$. A direct approach is potentially applicable to both categories (users and preparers) to study their viewpoints; on the other hand, an indirect approach is more heavily reliant on documentation, and for this reason it is more easily applicable to study the preparers' viewpoint. Indeed, preparers produce typical documental outputs (financial statements) that can be gathered and analysed in relation to variables; on the contrary, a user's typical documental output does not exist - therefore, to apply an indirect approach to the study of reasons, a variety of documental evidence (e.g. comment letters, companies' surveys) needs to be gathered based on individual contexts, as researchers cannot rely on the existence of standardized documental evidence to support their investigation.

After this brief review of the main characteristics of the potential direct and indirect approaches to study the reasons behind format choices, we can now conclude the examination of Table 1 analysing column 4. Indeed, in the latter it is possible to note that, while among studies on user-oriented reasons there are both investigative and narrative approaches, preparer-oriented reasons are always proposed with a narrative style. Moreover, until now, studies adopting an indirect approach have been based on financial statements only. 


\section{1l Macrothink}

International Journal of Accounting and Financial Reporting

ISSN 2162-3082

2016, Vol. 6, No. 2

Thus, an under-investigated research area emerges from the observation of Table 1: no study investigates the reasons behind format choices using a direct approach ${ }^{\text {vii }}$. Indeed, no study focuses exclusively on this critical issue. In fact, the titles of the relevant studies often address more the choices (what format do companies prefer?) instead of the reasons behind them (why do companies choose a specific format?).

Our research addresses this gap in the literature. The current study contributes to the "CI format choices" branch offering an article that uses a direct approach focusing on the preparers' opinions.

\section{Research Design}

Starting from the above literature, we transformed the Basic Research Aim ("To analyse the reasons of the preferred CIS format in EU countries with different accounting cultures") in a more precise Main Research Question - MRQ ('In the preparers' opinion, what reasons led to the CIS format preferences shown in the 2012 Annual Reports of Italian and British listed companies?").

The transformation implied decisions about the following aspects:

- the research approach to be used to study the reasons (i.e. preparers' viewpoint and their direct opinions);

- the countries representative of the two kinds addressed (i.e.: Italy and United Kingdom, respectively belonging to the European continental and the AngloSaxon accounting cultural contexts);

- the statistical population to be analysed (i.e. non-financial services listed companies);

- the financial statements to be analysed (i.e. consolidated annual reports) and their end dates (i.e. 2012).

Thus, to make the MRQ operative, we split it into three detailed research questions (DRQs). These have three different roles within the research, as Table 2 illustrates.

Table 2: Research design

Basic Research Aim:

To analyse the reasons of the preference for a CIS format

in European countries with different accounting cultures

Main Research Question (MRQ):

In the preparers' opinion, what reasons led to the CIS format preferences shown in 2012 Annual Reports of Italian and British non-financial services listed companies? 


\begin{tabular}{|l|l|l|l|}
\hline $\begin{array}{l}\text { Detailed Research } \\
\text { Question (DRQ) }\end{array}$ & $\begin{array}{l}\text { DRQ1: the CI deemed } \\
\text { useful by } \\
\text { stakeholders? }\end{array}$ & $\begin{array}{l}\text { What is the CIS } \\
\text { format of choice, } \\
\text { and has this format } \\
\text { been consistently } \\
\text { adopted? }\end{array}$ & $\begin{array}{l}\text { What are the reasons } \\
\text { involved in the choice } \\
\text { of the CIS format? }\end{array}$ \\
\hline Main issue & Usefulness & Format & Reasons \\
\hline Main role & Preliminary & Context & Research focus \\
\hline Data sources & Preparers (Questionnaire) & \\
\hline Tools of analysis & Descriptive Statistics & \\
\hline
\end{tabular}

Our research differs from the previous literature in two ways: a) although we analyse the preparers' viewpoint, we use a direct approach (based on the web-mail survey) instead of an indirect one based on the analysis of reporting outputs; b) among the many reasons detected, we included in the research a cultural reason (ease of preparation) different from those hitherto investigated or suggested.

\section{Methods}

This section presents the methods used for the sub-population (hereinafter: 'sample') selection, data collection and data analysis.

As for the sample selection, we considered the 2,797 (i.e. 317 Italian and 2,480 British companies) non-financial services companies listed on the main market of the Italian Stock Exchange and of the London Stock Exchange as of 31 December 2012. The final list of 295 companies (i.e. 82 Italian and 213 British companies) was obtained after a series of exclusions occurred (2,502 exclusions, i.e. 235 Italian companies and 2,267 British companies), as Panel B of Table 3 shows.

The sample Italy1 (82 Italian companies) obtained after the exclusions approximately represents $38 \%$ of the sample UK1 (213 British companies).

Table 3: Sample construction

Panel A - From all listed companies to the samples Italy1 and UK1

\begin{tabular}{|l|l|l|l|}
\hline & IT & UK & Tot. \\
\hline All listed companies & 317 & 2,480 & 2,797 \\
\hline Excluded companies & 235 & 2,267 & 2,502 \\
\hline
\end{tabular}




\begin{tabular}{|l|l|l|l|}
\hline Samples & $\begin{array}{l}82 \\
\text { (Italy1) }\end{array}$ & $\begin{array}{l}213 \\
\text { (UK1) }\end{array}$ & 295 \\
\hline
\end{tabular}

Panel B - Details on companies excluded from all listed companies

\begin{tabular}{|c|c|c|c|c|}
\hline Phase & Category of companies excluded & IT & UK & Tot. \\
\hline 1 & $\begin{array}{l}\text { Trading shares on the following markets: } \\
\text { MIV, AIMIT, MAC in Italy } \\
\text { AIM, PSM, SFM, trading only in the UK }\end{array}$ & 33 & 1,173 & 1,206 \\
\hline 2 & Foreign & 5 & 304 & 309 \\
\hline 3 & Non-service sectors & 130 & 216 & 346 \\
\hline 4 & Financial & 61 & 539 & 600 \\
\hline 5 & Suspended quotation & 0 & 2 & 2 \\
\hline 6 & $\begin{array}{l}\text { Different shares of the same company ( } 2 \mathrm{nd}, 3 \mathrm{rd} \text {, } \\
\text { etc.) }\end{array}$ & 5 & 0 & 5 \\
\hline 7 & Without website & 0 & 11 & 11 \\
\hline 8 & Without e-mail address & 1 & 14 & 15 \\
\hline 9 & Without investor relations section on the web-site* & 0 & 6 & 6 \\
\hline 10 & Not applying IASs/IFRSs & 0 & 1 & 1 \\
\hline 11 & Without OCI in the FS (with lawful permission) & 0 & 1 & 1 \\
\hline & Total & 235 & 2,267 & 2,502 \\
\hline
\end{tabular}

(*) These companies were excluded as the investor relations section of a company's website is the space typically including information essential to this research (e.g. contact details) or useful for factual checks on the information provided via questionnaire (e.g. financial statements).

As for the data collection (January 2014), we interviewed company representatives through a structured questionnaire ${ }^{\text {vii }}$ with closed answers including only one open-ended question. The questionnaire was administered online through Google Drive from April 2014 to August 


\section{I Macrothink}

International Journal of Accounting and Financial Reporting

ISSN 2162-3082 2016, Vol. 6, No. 2

2014. The questionnaire was composed of eight questions, as Table 4 shows. Data analysis and elaboration were carried out using statistical percentages.

Table 4. Questionnaire structure

\begin{tabular}{|c|c|c|c|}
\hline \multirow{2}{*}{$\begin{array}{l}\text { Relevant aspects } \\
\text { Q (Question) }\end{array}$} & \multicolumn{2}{|c|}{$\begin{array}{l}\text { Control question } \\
\text { data treatment) }\end{array}$} & \multirow{2}{*}{$\begin{array}{l}\text { Research } \\
\text { core }\end{array}$} \\
\hline & Respondents identity & $\begin{array}{l}\text { Information useful } \\
\text { for potential } \\
\text { exclusion }\end{array}$ & \\
\hline Q1 - Company name & $X$ & - & - \\
\hline Q2 - Consolidated statement & - & $X$ & - \\
\hline Q3 - OCI usefulness & - & - & $X$ \\
\hline Q4 - Format trend & - & - & $X$ \\
\hline Q5 - Format choice & - & - & $X$ \\
\hline Q6 - Reasons & - & - & $\mathrm{X}$ \\
\hline Q7 - Main reason & - & - & $X$ \\
\hline Q8 - Respondent identity & $X$ & - & - \\
\hline
\end{tabular}

\section{Results and Discussion}

\subsection{Answers received and section structure}

The questionnaire was administered to all 295 companies in the sample, and we received 80 answers (i.e. $27.12 \%$ of the sample). More in detail, we received $42^{\text {ix }}$ answers from Italian companies (Italy2, corresponding to $52 \%$ of Italy1) and 38 answers from British companies (UK2, equivalent to $18 \%$ of UK1). The final group of respondents is therefore of 80 companies. Results and discussion about answers received are presented in the following three sub-sections according to the DRQs they answered (see Table 5). 


\section{Mll Macrothink \\ International Journal of Accounting and Financial Reporting \\ ISSN 2162-3082 \\ 2016, Vol. 6, No. 2}

Table 5. Structure of section 5

\begin{tabular}{|c|c|c|c|}
\hline \multirow{2}{*}{$\begin{array}{l}\text { Detailed } \\
\text { Research } \\
\text { Question } \\
\text { (DRQ) }\end{array}$} & DRQ1 & DRQ2 & DRQ3 \\
\hline & $\begin{array}{l}\text { Is CI considered useful } \\
\text { for stakeholders? }\end{array}$ & $\begin{array}{l}\text { What is the preferred } \\
\text { CIS format and is this } \\
\text { choice constant? }\end{array}$ & $\begin{array}{l}\text { What are the reasons } \\
\text { behind CIS format } \\
\text { choices? }\end{array}$ \\
\hline \multirow{2}{*}{$\begin{array}{l}\text { Question } \\
\text { (Q) }\end{array}$} & Q3 & Q4, Q5 & Q6, Q7 \\
\hline & \multicolumn{3}{|l|}{$(\mathrm{Q} 1, \mathrm{Q} 2, \mathrm{Q} 8)^{*}$} \\
\hline Par. & 5.2 & 5.3 & 5.4 \\
\hline Contents & \multicolumn{3}{|l|}{ Results and discussion } \\
\hline
\end{tabular}

(*) Question 1 and 8 are questions useful to identify the respondents' identity, while Question 2 on Consolidated Statement is useful for further exclusions.

In the remainder of this section, the results are presented according to the subpopulation to which they belong (Italy2 or UK2).

\subsection{Results and discussion of Detailed Research Question 1 (DRQ1)}

To answer DRQ1 about CI usefulness for stakeholders, we asked the companies Question 3 (Q3): "Since 2009, IAS 1 has required the disclosure in the Income Statement of a final result (Comprehensive income) as the sum of the traditional Profit/Loss and the Other Comprehensive Income items (OCI). How useful is this new information for each of the following reader categories?". The companies were requested to indicate the usefulness for each proposed category (Current shareholders, Potential shareholders, Banks and other lenders, Customers, Suppliers and Unions ${ }^{\mathrm{x}}$ ) choosing 1 if the information was considered "very useful", 2 if it was "useful", 3 if it was "not very useful" and 4 if it was "useless". Graph 1 shows the results obtained. 


\section{Macrothink}

Graph 1. Results on Question 3: Italian and British preparers' opinion on

CI usefulness for Financial Statements users
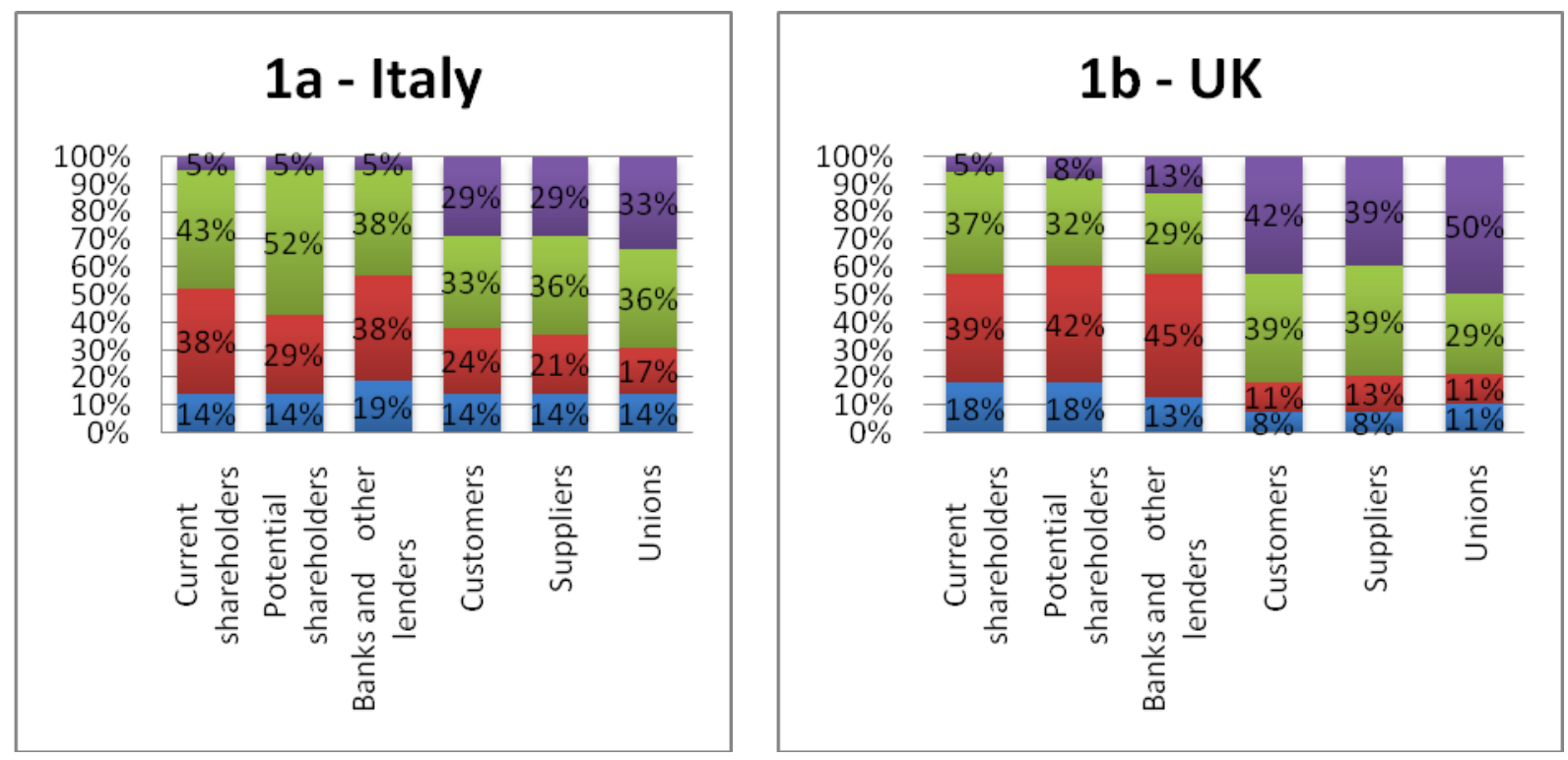

Very useful E Useful Not very useful Eseless

At a first glance, intermediate options ("useful" and "not very useful") are the most ticked for the first three categories of stakeholders (Current shareholders, Potential shareholders, Banks and other lenders) in both national groups, while more negative options ("not very useful" and "useless") are the most ticked for the last three categories of stakeholders (Customers, Suppliers and Unions), again for both national groups. The preparers' opinions appear therefore unbalanced toward some categories rather than others.

When "useful" and "very useful" answers are summed, DRQ1-related results about CI usefulness confirm a substantial likeness between Italian and British respondents (see Graph 1). Their similarity shows in the division of stakeholders into two separate groups, i.e. a first group that preparers deem more interested in CI, and a second group that preparers deem less interested in CI (see blue and red areas in Graph 1). The first group could be defined as the 'financial' group, as it includes shareholders (current and potential) and lenders (e.g. banks). The second group could be defined as the 'operative' group, as it includes stakeholders related to commercial operation and labour. As we expected, preparers think that subjects involved with financial issues are more interested in CI than others. However, British companies show a wider gap in the perceived interest for the two groups. This means that, when Financial Statements are prepared, British preparers emphasize their CI orientation to 'financial' stakeholders, as the IASB framework requests (IASB 2012, 1), more than Italian preparers do. Banks and other lenders are deemed the stakeholder category most interested in CI, even more by British preparers than their Italian counterparts, contrary to our expectations (based on the weakness of the Italian capital market and the strong requirements 
traditionally expressed by Italian banks on companies' financial statements).

\subsection{Results and discussion of Detailed Research Question 2 (DRQ2)}

To answer DRQ2 about the preferred CIS format and the stability of this choice, we asked companies Question 4 (Q4) and Question 5 (Q5).

Q4 was: "Since 2009, IAS 1 has allowed to draw up an Income Statement consisting of one or two statements. Since then, has your company always used the same format?". The companies could answer only "yes", "no" or "I don't know". Table 6 shows the results of this question.

Table 6. Results on Question 4: Italian and British preparers' answers

on the stability of the CI format trend

\begin{tabular}{|l|l|l|l|l|}
\hline \multirow{2}{*}{$\begin{array}{l}\text { Country } \\
\text { Values }\end{array}$} & \multicolumn{2}{|l|}{ Italy } & \multicolumn{2}{l|}{ UK } \\
\cline { 2 - 5 } Answer & No. & $\%$ & No. & $\%$ \\
\hline Yes & 39 & 92.86 & 29 & 76.32 \\
\hline No & $2 *$ & 4.76 & $4 * *$ & 10.53 \\
\hline I don't know & 1 & 2.38 & 5 & 13.16 \\
\hline Tot. & 42 & 100.00 & 38 & 100.00 \\
\hline
\end{tabular}

(*) In 2012, one company out of the two chose the two-statement format

(**) In 2012, two companies out four chose the two-statement format

Although the majority of both Italian and British preparers declare that since 2009 (the year of first adoption of IAS 1 revised 2007) their company has used the same format, Italian companies have higher levels of consistent format use than their British counterparts. In fact, only $4.76 \%$ of companies (in Italy) against $10.53 \%$ (in the United Kingdom) have indicated format changes over the years. Moreover, half of both Italian and British companies that claimed a format change also stated that in 2012 they moved over to the two-statement format (see table notes). Therefore, format type and format changes over the years seem unrelated. Finally, "I don't know" percentages show that Italian respondents appear more aware of their company's format choice over the time than British respondents.

As for Q5, the question was: “In 2012, which format of Income Statement did you choose?”. The companies could answer only "Two statements" or "One statement". Table 7 shows the results. From Table 7 emerges that the results are consistent with those of previous studies 


\section{1ll Macrothink}

International Journal of Accounting and Financial Reporting

ISSN 2162-3082

2016, Vol. 6, No. 2

about the format chosen by the companies operating within the two geographical contexts this research addresses ${ }^{\mathrm{xi}}$. The prevalent choice is the two-statement format in both countries, although with a higher percentage in the UK $(73.88 \%)$ than in Italy $(66.67 \%)$. These findings appear very interesting given that British preparers had prior knowledge of CI, as opposed to their Italian counterparts.

Table 7. Question 5 (Q5): Italian and British preparers' answers on the CI format chosen in the Financial Statements 2012

\begin{tabular}{|c|c|c|c|c|}
\hline \multirow{2}{*}{$\begin{array}{l}\text { Country } \\
\text { Value } \\
\text { Answer }\end{array}$} & \multicolumn{2}{|c|}{ Italy } & \multicolumn{2}{|l|}{ UK } \\
\hline & No. & $\%$ & No. & $\%$ \\
\hline Two statements & 28 & 66.67 & 28 & 73.68 \\
\hline One statement & 14 & 33.33 & 10 & 26.32 \\
\hline Tot. & 42 & 100.00 & 38 & 100.00 \\
\hline
\end{tabular}

5.4 Results and discussion of Detailed Research Question 3 (DRQ3)

To answer DRQ3 about the reasons behind CIS format choices, we formulated two different Questions 6 (Q6a and Q6b) for different groups of respondents, according to the format chosen. The first group of respondents (those who selected the two-statement format when they answered Q5) were given Question 6a (Q6a): "How important was each of the following reasons for the "two-statement format" chosen in 2012?". We asked companies to indicate the importance of each reasons ("It is the easiest format to prepare", "It is the easiest format for readers", "Financial Statement readers are very interested in Profit/Loss xii", "The existence or not of the Other Comprehensive Income (OCI)", "The size of the OCI" and "The sign of the OCI"); 1 was very important, 2 was important, 3 was of little importance and 4 was irrelevant. Graph 2 shows the results for the two-statement respondents. 


\section{Macrothink \\ International Journal of Accounting and Financial Reporting \\ ISSN 2162-3082 2016, Vol. 6, No. 2}

Graph. 2. Results on Question 6a: Italian and British preparers' answers

on the importance of format choice reasons

in the 2012 Financial Statements - Two-statement respondents
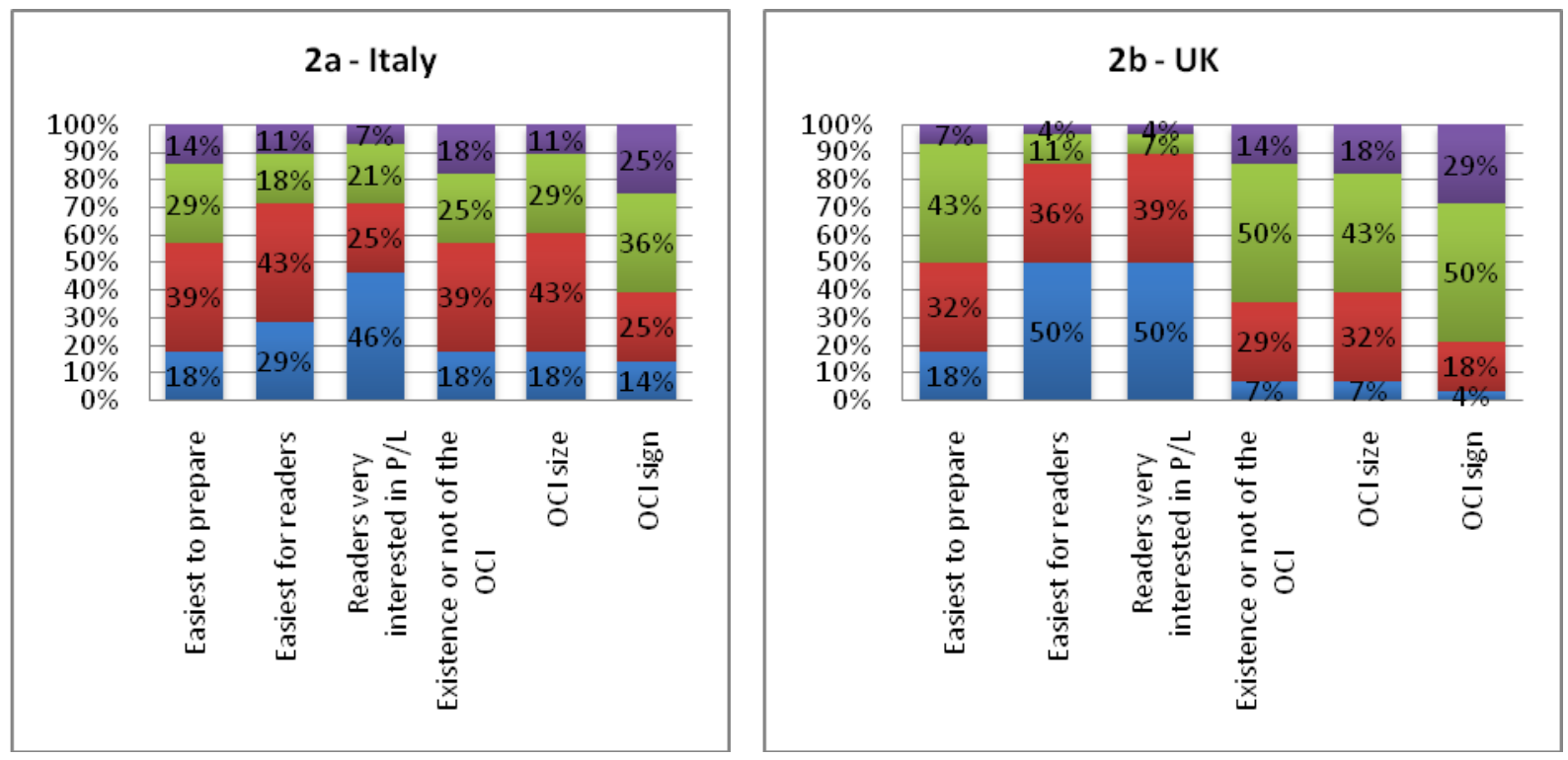

very important $\quad$ Important $\quad$ Of little importance $\quad$ Irrelevant

Graph 2 shows that, as for the two-statement format choices:

- if we focus on "very important" answers (in blue in the graph), two 'reader-related' reasons predominate: a) the format is the easiest for readers (29\% in Italy and 50\% in the United Kingdom); b) readers are very interested in P/L (46\% in Italy and $50 \%$ in the United Kingdom);

- grouping "very important" and "important" answers to each reason proposed (see blue and red areas of Graph 2) and then ranking the percentages obtained, the same reasons highlighted above emerge with stronger percentages: a) the format is the easiest for readers (72\% in Italy and $86 \%$ in United Kingdom); b) readers are very interested in P/L (71\% in Italy and $89 \%$ in United Kingdom). This means that preparers deem the two-statement format the best way to expose P/L. The two main reasons discussed are followed by different reasons in the two countries. More in detail, in the British respondents' opinion, the preparer-oriented reason follows (e.g. the ease of preparation is quoted by $50 \%$ of respondents as important/very important) and the remaining OCI-related reasons close the ranking. On the contrary, for Italian respondents OCI size emerges as ranking third (it is quoted by $61 \%$ as important/very important); this is followed ex aequo by the ease of preparation and the OCI existence (both quoted by $57 \%$ as important/very important); the OCI sign closes the ranking, as in the UK. In this framework the 
preparer-oriented reason we inserted in this research emerges as an intermediateranking reason;

- while Italian preparers split the reasons in three main categories (the highest, the lowest and the intermediate), British preparers have responded with more clear-cut views about the reasons deemed less important (i.e. OCI-related reasons). For both countries, the OCI-related group is the least important (in Italy) or anyway not the most important group of reasons (in the UK). A noteworthy point is that, when scholars statistically investigated these OCI-related reasons in the Italian context, they generally found no or weak association with the format (e.g. De Cristofaro \& Falzago, 2014); this seems inconsistent with our findings, as Italian preparers have attributed higher relevance to the OCI-group of reasons than their English counterparts in this study.

- the above-mentioned low importance of OCI-related reasons (i.e. company-related reasons) for British companies well matches with their higher interest in readerrelated reasons. This indicates a slightly higher orientation towards (or awareness of) the link between format and readers' needs in British than Italian companies. On the contrary, Italian respondents seem to be more concerned about preparers' needs than British respondents are (see the first reason in Graph 2).

The second group of respondents (those who selected the one-statement format), was asked Question 6b (Q6b): "How important was each of the following reasons for the "one-statement format" chosen in 2012?". The same possible answers as for Q6a were provided. The only difference was that $\mathrm{P} / \mathrm{L}$ was replaced with $\mathrm{CI}$ when respondents were asked about the performance measure that preparers believe readers are interested in. Graph 3 shows the results obtained from the one-statement respondents. 


\section{I Macrothink}

International Journal of Accounting and Financial Reporting

Graph 3. Results on Question 6: Italian and British preparers' answers

on the importance of the CI format choice reasons

in the 2012 Financial Statements - One-statement respondents
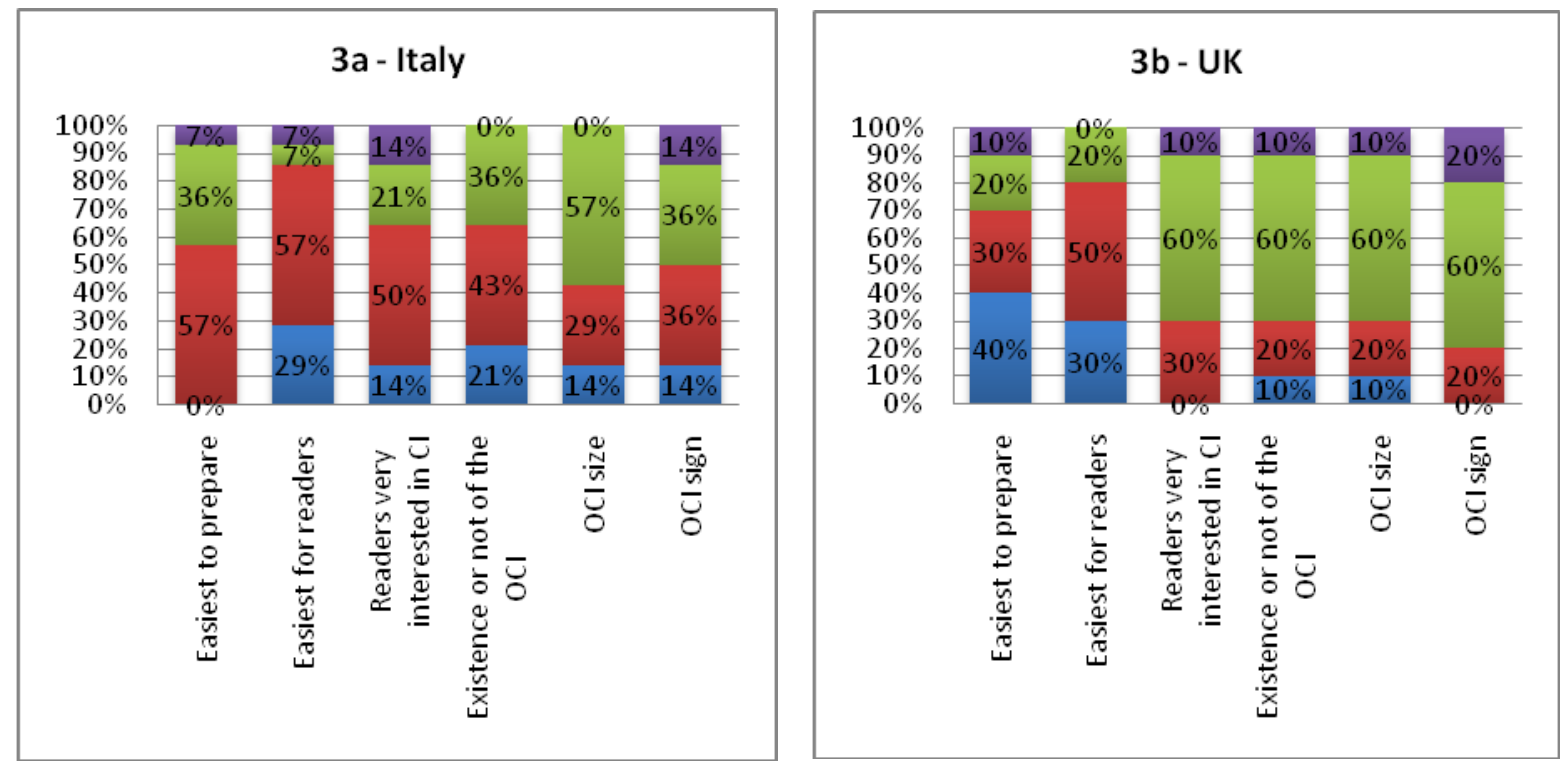

\section{Very important $\quad$ Important $\quad$ Of little importance Irrelevant}

With regard to the one-statement respondents, there are both similarities and differences between Italian and British companies. Focusing on the similarities (see Graph 3), if the "very important" and "important" responses are added together, the most quoted reason is the ease for readers ( $86 \%$ in Italy and $80 \%$ in the United Kingdom).

On the contrary, some interesting differences have also emerged ${ }^{\text {xiii. }}$ :

- if "very important" and "important" answers are added together, the Italian graph shows a gradually decreasing ranking of the reasons proposed (ranging from $86 \%$ for the ease of reading to $43 \%$ for OCI size); British responses, on the other hand, generate a well-defined division between two groups of reasons. The first group includes the only two reasons deemed relevant (i.e. reasons related to ease of preparation/reading, whose percentages range between $70 \%$ and $80 \%$ ). The second group includes the remaining answers (with percentages ranging between $20 \%$ and $30 \%)$

- while Italian preparers consider relevant both the interest in CI and the existence of the OCI (the sum of important and very important responses of Graph 3 is 64\% for both), fewer British preparers consider them relevant (the sum of important and very important responses of Graph 3 is $30 \%$ for both). Thus, while Italian preparers reveal that they chose the one-statement format because users could be interested in the new performance measure, British preparers do not think the 
same. Paradoxically, in the one of the two countries where CI is a well-known measure (UK), users' interest in CI does not seem to constitute a reason orienting companies toward a one-statement format. On the contrary, although CI is a less well-known measure in Italy, users' interest in CI seems to be a factor pushing preparers toward a one-statement format. Hence, we can state that the onestatement format, i.e. the format that more emphasizes CI, satisfies users' expectations on performance measures only in the Italian context. On the contrary, when British preparers choose such a format, they are unlikely to be doing so in light of the performance measure in which users could be interested.

Finally, to fully understand the reasons behind CIS format choices, we asked Italian and British preparers to indicate the most important reason for their choice. In this case we analysed their answers considering two-statement and one-statement responses together.

Question 7 (Q7) was: "Among the reasons proposed in the previous question, which is the main one?". We asked companies to indicate only one of the reasons proposed in Question 6, adding also an 'other' field to allow preparers to suggest reasons different from the ones listed. Graph 4 shows the results organizing them by format chosen and by country.

Graph 4. Results on Question 7: Italian and British preparers' answers on the most important reason for the CI format choice in the FS 2012: a format-based comparison*
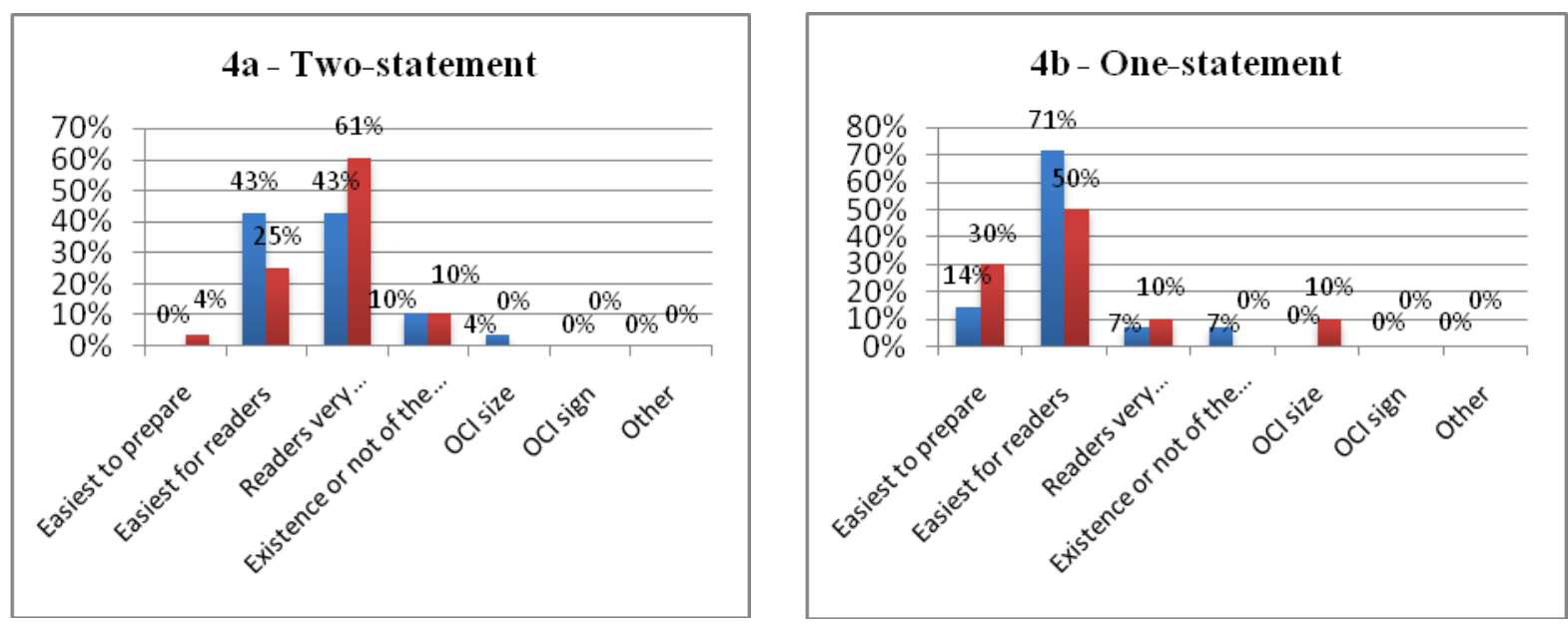

$$
=\mathrm{ITA}=\mathrm{UK}
$$

(*) The third reason proposed (i.e. readers are very interested in a performance measure) was about the interest in $\mathrm{P} / \mathrm{L}$ for two-statement respondents and about the interest in $\mathrm{CI}$ for onestatement respondents.

Regarding two-statement respondents, Italian companies have emphasized the two highest ranking reasons in Graph 2 (both 43\%), while British respondents are definitely oriented 


\section{Mll Macrothink}

International Journal of Accounting and Financial Reporting

ISSN 2162-3082 2016, Vol. 6, No. 2

toward the users' interest in $\mathrm{P} / \mathrm{L}(61 \%)$. British preparers seem to confirm a higher degree of orientation toward the performance measure representation, while Italian preparers show a greater interest in ease of reading. The two data sets show a general agreement on the ranking of the main influential reason in Italy and the UK (Graph 4).

As for the one-statement respondents, results confirm our expectations (ease of reading is the highest ranking reason), although Italian respondents are more decisively oriented to this answer (about $70 \%$ for Italy compared with $50 \%$ for the UK). British respondents also consider ease of preparation as important (about 30\%). This means that in both countries, simplicity in reading/preparation is the top reason directing format choices.

Graph 4 also underlines the similarities between the two countries, as it shows that both groups of preparers agree about the same two "top reasons" for the same format. For the twostatement format, these are ease of reading (43\% in Italy and 25\% in the United Kingdom) and readers' interest in P/L ( $43 \%$ and $61 \%$ respectively); for the one-statement format, these are ease of reading (71\% in Italy and 50\% in the United Kingdom) and ease of preparation (14\% in Italy and 30\% in the United Kingdom).

Moreover, the new reason introduced in this study (ease for preparers) shows a different degree of success in Graphs 2, 3 and 4. In fact, while in Graphs 2 and 3 this reason is rated as important with percentages ranging between 50 and $70 \%$ of respondents, the same reason is rated less often as the most important in Graph 4, being more prevalent in the case of the onestatement format and for British preparers. This suggests that the two countries perceive differently the difficulties related to using the two formats.

Finally, no reasons different from the ones suggested in the questionnaire were reported by respondents.

\section{Summary, Limitations and Conclusions}

While American scholars were interested in the Comprehensive Income (CI) already in the $20^{\text {th }}$ century, European scholars have enhanced their interest in the subject only in more recent times, i.e. after the European Union's adoption of IAS 1. As a result, the relevant literature framework is actually composed of several U.S. context-oriented studies, emerging EU context-oriented studies and sporadic studies on other regions of the world. Since tools of direct analysis (e.g. surveys, interviews, comment letters, etc.) were neglected when these studies investigated preparers' CIS format choices, our research has investigated the reasons behind the format choices of Italian and British preparers using a survey-based direct approach.

To this aim, three detailed research questions were set: DRQ1 (CI usefulness for stakeholders), DRQ2 (CIS format choice and its trend) and DRQ3 (reasons for CIS format choices).

The survey findings can be summarized as follows:

- in both countries, preparers deem that CI is a performance measure mainly useful to 'financial' stakeholders (DRQ1); 


\section{MInstitute Macrothink $_{\text {Int }}$}

International Journal of Accounting and Financial Reporting

- in both countries, the two-statement format (mainly in the UK) and its stability (mainly in Italy) prevail. The choice of format does not influence its consistent use (DRQ2);

- both categories of preparers agree about: (i) the two main reasons that led to the format choice; these are reader-oriented reasons, when a two-statement format is selected, and both reader/preparer-oriented reasons, when a one-statement format is selected; (ii) preferences for easy reading in the case of the one-statement format; on the contrary, in case of two-statement, while British preparers mainly focus on the interest in P/L, Italian preparers focus also on the ease of reading; (iii) the group of reasons of least influence in the choice of format, i.e. OCI-related reasons; this result confirms that OCI features do not drive CIS format choices, like previous empirical studies found (e.g. Cimini 2013 and De Cristofaro-Falzago 2014). Hence, another aspect emerges: while British preparers ultimately focus on one reason (the interest in $\mathrm{P} / \mathrm{L}$ or ease of reading), Italian preparers focus on one reason only in the case of the one-statement format (ease of reading), while they deem important both ease of reading and interest in $\mathrm{P} / \mathrm{L}$ in the case of the twostatement format (DRQ3);

- British preparers emphasize the easy preparation of financial statements for both formats (i.e. the preparer-oriented reason this research added) more than the 'nonCI-accustomed' Italian respondents (differently from what could be reasonably expected, given the previous experience of the British accounting tradition with FRS 3). Although this reason cannot be considered as the main reason driving format choices, it represents a significant addition contributed by this study;

- since no further reasons were proposed by respondents, this study could be reasonably claimed to have covered the reasons considered most important by respondents.

Despite the slight differences found when responses examined by format ${ }^{\mathrm{xiv}}$ and by country ${ }^{\mathrm{xv}}$ are compared, both Italy and the United Kingdom are basically aligned in their views about the reasons supporting their format choices. Hence, contrary to expectations, countries with different financial markets and different accounting cultures chose the same CIS formats mainly because of the same reader-oriented reasons (followed by preparer-oriented ones).

These findings are important also because they shed a new light on the official positions that national accounting standards boards assumed over the years about IASB's proposals of IAS 1 revisions. More in detail, it has to be recalled that:

(i) at first, OIC agreed with the elimination of the two-statement option (OIC 2009), while subsequently they changed their view, considering inopportune and premature such elimination (OIC 2010);

(ii) at first, ASB did not agree with the two-statement elimination (ASB 2006 and ASB 2009), because this was deemed more consistent with user expectations and general practice; subsequently (ASB 2010), although ASB admitted that the two-statement format elimination 
would not have had "any significant impact on the consistency and comparability of financial statements", they supported the introduction of the single statement format only.

In both cases the Boards refer to user opinions, but while OIC retracted its first position in order to support the two-statement format, ASB first supported the latter and later showed a preference for the single-statement format. Therefore, despite similar findings about format choices and their related reasons for both countries analysed, opposite shifts are observable within the positions of Italian and British accounting standard boards.

As for the value of this study, the survey carried out in this research showed how a direct approach can be used to enhance pre-existing knowledge of the reasons behind the preparers' format choice. Regarding the limitations of this research, we can highlight the following:

- since we investigated only non-financial services companies, the research does not represent all the listed companies of the countries considered;

- when we asked for the respondents' opinions about CI usefulness for stakeholders, some categories were omitted (e.g. "Governments and their agencies");

- the percentage of British respondents (18\% of the sample) is lower than its Italian equivalent (52\%); this reduces the comparability of the country-related results;

- the answers obtained were not statistically calibrated with corporate features such as the number of employees, their assets, etc. ${ }^{1}$

The above considerations highlight the existence of some research areas that could be further investigated. More in detail, widening the scope to other countries where IASs/IFRSs are applied and using a direct approach can be suggested as a way to enrich the literature branch on CI presentation devoted to reasons of CIS format choices.

Finally, it would be appropriate to further update the study of the British CIS format choices and related reasons after the result of the "Brexit" referendum (June 2016). The UK's exit from the European Union could imply, among other consequences, the return to the national GAAPs for all British companies. This would modify the CIS format options and would decrease the financial reporting comparability across Europe.

\section{References}

ASB - Accounting Standards Board (1992). FRS 3 Reporting Financial Performance.

ASB - Accounting Standards Board (2006). Comment letter 9 to IASB Exposure Draft "Proposed Amendments to IAS 1 Presentation of Financial Statements - A Revised Presentation" of March 2006.

ASB - Accounting Standards Board (2009). Comment letter 14 to FASB \& IASB Discussion

\footnotetext{
${ }^{1}$ On the benefits of avoiding a distortion results, see Deville and Särndal (1992).
} 
Paper "Preliminary Views on Financial Statement Presentation" of October 2008.

ASB - Accounting Standards Board (2010). Comment letter 10 to IASB Exposure Draft "Presentation of Items of Other Comprehensive Income Proposed amendments to IAS 1" of May 2010.

Agostini M. \& Marcon C. (2013). Comprehensive Income (CI) Statement's Compliance With International Accounting Standard (IAS) 1 (Revised 2007 and 2011): Evidence From Italian Listed Corporate Groups, Journal of Modern Accounting and Auditing, 9(1), 1-19.

Cimini (2013). Reporting Comprehensive income issues: empirical evidence from France, Germany and Italy, Economia Aziendale Online, 4(1), 1-17.

De Cristofaro T. \& Falzago B. (2014). What trend for Comprehensive Income presentation? Evidence from Italy, International Journal of Accounting and Taxation, 2(3), 17-40.

De la Rosa D. \& Szychta, A., (2012). Comprehensive income presentation under IAS 1: the reporting practices of the largest companies listed on the Warsaw Stock Exchange. Zeszyty Teoretyczne Rachunkowości, 68, 121-145.

Deville J.C. \& Särndal (1992). Calibration estimators in survey sampling. Journal of the American statistical Association, 87(418), 376-382.

Doni, F., Verona, R. \& Rossetti, S. (2013), The Performance Reporting Choices In Europe And Usa. A Survey On The "Successful" Convergence Ifrs/Us-Gaap After The Adoption Of Ias 1 Revised, Paper presented at AIDEA Bicentenary Conference, Lecce, September, $19^{\text {th }}$ $21^{\text {st }} 2013$.

Du, N., Stevens, K. \& McEnroe, J. (2015). The effects of comprehensive income on investors' judgments. Accounting Research Journal, 28(5), 284-299.

Enquist, K. \& Magnerius, M. (2014). A Practical Approach to Other Comprehensive Income:

Does Anyone Really Care? BSc Thesis within Accounting and Financial Management, course 639, 18-19.

Financial Accounting Standards Board (1997). Statement of Financial Accounting StandardsSFAS 130. Reporting Comprehensive Income.

Financial Accounting Standards Board (2011). Update 2011-05, Comprehensive Income (Topic 220): Presentation of Comprehensive Income.

Ferraro O. (2011). Comprehensive Income in Italy: Reporting Preferences and its Effects on Performance Indicators, Journal of Modern Accounting and Auditing, 7(12), 1315-1328.

Ferraro O. (2012). Comprehensive Income Disclosures: evidence from Italy, Accounting \& Taxation, 4(2), 65-76.

Frendzel, M., \& Szychta, A. (2013). Challenges for Finance and Accounting. Comprehensive Income reporting: Empirical Evidence from the Warsaw Stock Exchange. Social Sciences, 4(82), 7-16. 


\section{I Macrothink}

International Journal of Accounting and Financial Reporting

ISSN 2162-3082

2016, Vol. 6, No. 2

Gazzola P. \& Amelio S. (2012). One or Two Statement Approach for the Income Statement Presentation of Czech Companies?, Trends Economics and Management, 6(12), 29-41.

Gazzola P. \& Amelio S. (2014). Is total comprehensive income or net income better for the evaluation of companies' financial performance?, Central European Review of Economics, 17, $39-51$.

Haller A. \& M. (2013), The impact of national GAAP and accounting traditions on IFRS policy selection: Evidence from Germany and the UK, 22(1), 39- 56.

Huff, K., \& Delcoure, N. N. (2014). The Method of Choice for Reporting Comprehensive Income. Journal of Eastern European and Central Asian Research (JEECAR), 1(2), 1-5.

IASB - International Accounting Standards Board (2007) IAS 1 Presentation of Financial Statements, revised version of 2007.

IASB - International Accounting Standards Board (2011). Presentation of Financial Statements. International Accounting Standard (IAS) No. 1.

IASB - International Accounting Standards Board (2012). Technical Summary of the Conceptual Framework for Financial Reporting 2011.

IASB - International Accounting Standards Board (2015). Framework for the Preparation and Presentation.

Maines L.A. \& McDaniel L.S. (2000). Effects of Comprehensive Income-Characteristics on Nonprofessional Investors' Judgments: The Role of Financial Statement Presentation Format, The Accounting Review, 75(2), April, 179-207.

Ngmenipuo I. M. (2014). Reporting Comprehensive Income Issues Empirical Evidence from Ghana, International Journal of Economics, Commerce and Management, 2(12), 1-22.

Nobes, C. (1998). Towards a general model of the reasons for international differences in financial reporting. Abacus, 34(2), 162-187.

OIC - Organismo Italiano di Contabilità (2009). Comment letter 147 to FASB \& IASB Discussion Paper "Preliminary Views on Financial Statement Presentation" of October 2008.

OIC - Organismo Italiano di Contabilità (2010). Comment letter 46 to IASB Exposure Draft "Presentation of Items of Other Comprehensive Income Proposed amendments to IAS 1" of May 2010.

Pandit G.M., Phillips J.J. (2004). Comprehensive Income: Reporting Preferences of Public Companies, The CPA Journal, 74(11), 40-41.

Pandit, M., Rubenfield, A., \& Phillips, J.J. (2006). Current NASDAQ Corporation Methods of Reporting Comprehensive Income. Mid-American Journal of Business, 21(1), Spring, 1320. 


\title{
II Macrothink \\ International Journal of Accounting and Financial Reporting \\ ISSN 2162-3082 \\ 2016, Vol. 6, No. 2
}

\section{Copyright Disclaimer}

Copyright for this article is retained by the author(s), with first publication rights granted to the journal.

This is an open-access article distributed under the terms and conditions of the Creative Commons Attribution license (http://creativecommons.org/licenses/by/3.0/).

\footnotetext{
${ }^{\mathrm{i}} \mathrm{i}$ Even if the paper comes from a joint research work of authors, sections 3, 4, 5.1, 5.3 and 5.4 are to be attributed to Barbara Falzago, while sections 1, 2, 5.2 and 6 are to be attributed to Tiziana De Cristofaro.

\begin{abstract}
ii Although the CI concept has North-American origins, the U.S. FASB issued SFAS 130 in 1997, i.e. some years later than ASB. This standard introduced two performance-based options and a third nonperformance-based (Statement of Changes in Equity) option for the OCI presentation. Subsequently, with the FASB Accounting Standards Update (ASU) 2011-05, the third option was eliminated.
\end{abstract}

\begin{abstract}
iii Note that the 2011 IAS 1 version does not substantially change the two options because its $\S 10$ A only regulates the position of the statements composing the two-statement format and the recycling of OCI items.
\end{abstract}

iv About main European Anglo-Saxon and continental accounting systems features see Nobes $(1998,168$ 170).

${ }^{v}$ The preferred format in Italy and in the United Kingdom is the two-statement as shown by previous studies (e.g., Huff \& Delcoure, 2014).

\footnotetext{
${ }^{\text {vi }}$ When such variables were separately considered, weak or no links with the format were found, while when more variables were simultaneously included in a regression study, a moderate association was found.
}

vii The direct approach was used to analyse issues slightly different than reasons of format choices. For example, Maines \& McDaniel (2000) used a questionnaire to explore the effects of SFAS 130 Income Statement formats on US non-professional investors' decisions. Similarly, Du et. al. (2015) elicited graduate students in order to analyse the effects of different CIS presentations on non-professional investors' judgements. Finally, a BSc thesis by Enquist \& Magnerius (2014) used 2013 comment letters to study preparers' positions about the importance of $\mathrm{P} / \mathrm{L}$ as performance measure and the utility of the OCI's recycling.

viii The questionnaire will be provided upon request. 
ix One company out of the initial set of 43 questionnaires received declared they did not prepare the consolidated financial statement considered in this study, and their response was therefore excluded from the sample.

${ }^{x}$ Note that we indicated only some of the possible stakeholders. For example, the IASB Framework of 2015 indicates also other categories such as "Governments and their agencies" and "Public".

${ }^{x i}$ For studies revealing the preference of the two-statement format in both countries see: Agostini \& Marcon 2013, Cimini 2013, De Cristofaro \& Falzago 2014, Doni et al. 2013, Ferraro 2011, Ferraro 2012, Haller \& Wehrfritz 2013, Huff \& Delcoure 2014.

xii $\mathrm{P} / \mathrm{L}$ became $\mathrm{Cl}$ for companies that chose the one-statement format.

xiii These may be due the low number of one-statement format choices.

xiv Mainly reader-oriented reasons are found for the two-statement format, while also preparer-oriented reasons are found for the one-statement format.

${ }^{x v}$ Peaks both for ease of reading of Italian one-statement CIS and for interest in P/L for British twostatement CIS are observable. 